\title{
Excess Molar Volumes and Viscosities for the Binary Mixtures of n-Octane, n-Decane, n-Dodecane, and n-Tetradecane with Octan-2-ol at $298.15 \mathrm{~K}$
}

\author{
Arvind R. Mahajan and Sunil R. Mirgane \\ P. G. Department of Chemistry, Jalna Education Society's R. G. Bagdia Arts, R. Benzonji Science College, \\ S. B. Lakhotia Commerce, Jalna, Maharashtra 431 203, India \\ Correspondence should be addressed to Arvind R. Mahajan; marvind22@yahoo.co.in
}

Received 4 April 2013; Accepted 2 June 2013

Academic Editor: M. A. Rosen

Copyright (c) 2013 A. R. Mahajan and S. R. Mirgane. This is an open access article distributed under the Creative Commons Attribution License, which permits unrestricted use, distribution, and reproduction in any medium, provided the original work is properly cited.

\begin{abstract}
Experimental values of densities $(\rho)$ and viscosities $(\eta)$ in the binary mixtures of $\mathrm{n}$-octane, $\mathrm{n}$-decane, $\mathrm{n}$-dodecane, and $\mathrm{n}$-tetradecane with octan-2-ol are presented over the whole range of mixture composition at $T=298.15 \mathrm{~K}$. From these data, excess molar volume $\left(V_{m}^{E}\right)$, deviations in viscosity $(\Delta \eta)$, and excess Gibbs free energy of activation $\Delta G^{* E}$ have been calculated. These results were fitted to Redlich-Kister polynomial equations to estimate the binary coefficients and standard errors. Jouyban-Acree model is used to correlate the experimental values of density and viscosity at $T=298.15 \mathrm{~K}$. The values of $V_{m}^{E}$ have been analyzed using PrigogineFlory-Patterson (PFP) theory. The results of the viscosity composition are discussed in the light of various viscosity equations suggested by Grunberg-Nissan, Tamara and Kurata, Hind et al., Katti and Chaudhri, Heric, Heric and Brewer, and McAllister multibody model. The values of $\Delta \ln \eta$ have also been analyzed using Bloomfield and Dewan model. The experiments on the constituted binaries are analyzed to discuss the nature and strength of intermolecular interactions in these mixtures.
\end{abstract}

\section{Introduction}

Density and viscosity data for liquid mixtures are important from practical and theoretical points of view. Experimental measurements of these properties for binary mixtures have gained much importance in many chemical industries and engineering disciplines [1]. Experimental liquid viscosities of pure hydrocarbons and their mixtures are needed for the design of chemical processes where heat and mass transfer and fluid mechanics are important. Prediction of the liquid behavior of hydrocarbon mixture viscosities is not yet possible within the experimental uncertainty. Therefore, experimental measurements are needed to understand the fundamental behavior of this property and then to develop new models [2]. Alkanes are important series of homologous, nonpolar, and organic solvents. They have often been used in the study of solute dynamics because their physicochemical properties as a function of chain length are well-known [3]. They are also employed in a large range of chemical processes [4]. The physicochemical properties play an important role in the understanding of several industrial processes. Properties such as viscosity or surface tension are required in many empirical equations for different operations such as mass and heat transfer processes. For example, it is necessary to know the mass transfer coefficient to design gas-liquid contactors. To determine the equations that modelize the mass transfer process requires knowledge of the density, viscosity, and surface tension of the liquid phase [5].

Viscosities and excess molar volumes of binary mixtures of methylbenzene [6] and methylcyclohexane [7] with octan2 -ol at $T=298.15 \mathrm{~K}$ are only reported. To the best of our knowledge, the properties of the binary mixtures of n-octane, $\mathrm{n}$-decane, $\mathrm{n}$-dodecane, and n-tetradecane with octan-2-ol have not been reported earlier.

In the present paper, we report density and viscosity data for the binary mixtures of n-octane, $n$-decane, n-dodecane, and n-tetradecane with octan-2-ol $T=298.15 \mathrm{~K}$. This work will also provide a test of various semiempirical equations 
to correlate viscosity of binary mixtures. The types of used relations are Tamara and Kurata, Heric, Heric and Brewer, Hind et al., Katti and Chaudhri, and McAllister multibody model.

\section{Experimental}

Chemicals used in the present study were of analytical grade and supplied by S.D. Fine Chemicals Pvt Ltd. Mumbai with quoted mass fraction purities: n-octane $(>0.99)$, n-decane (>99.6), n-dodecane (>99.8), and n-tetradecane (>99.7). Octan-2-ol (purity >99.3) was supplied by E-Merck. Prior to use, all liquids were stored over $0.4 \mathrm{~nm}$ molecular sieves to reduce the water content and were degassed. The binary mixtures of varying composition were prepared by mass in special air-tight bottles. The masses were recorded on a Mettler balance to an accuracy of $\pm 1 \times 10^{-5} \mathrm{~g}$. Care was taken to avoid evaporation and contamination during mixing. The estimated uncertainty in mole fraction was $<1 \times 10^{-4}$.

The densities of the solutions were measured using a single capillary pycnometer made up of borosil glass with a bulb of $8 \mathrm{~cm}^{3}$, and capillary with internal diameter of $0.1 \mathrm{~cm}$ was chosen for the present work. The detailed pertaining to calibration, experimental set up, and operational procedure has been previously described [6-10]. An average of triplicate measurement was taken in to account. The reproducibility of density measurement was $\pm 3 \times 10^{-5} \mathrm{~g} / \mathrm{cm}^{3}$.

The dynamic viscosities were measured using an Ubbelohde suspended level viscometer [6-10] calibrated with conductivity water. An electronic digital stop watch with readability of $\pm 0.01 \mathrm{~s}$ was used for the flow time measurements. At least three repetitions of each data reproducible to $\pm 0.05 \mathrm{~s}$ were obtained, and the results were averaged. Since all flow times were greater than $300 \mathrm{~s}$ and capillary radius $(0.1 \mathrm{~mm})$ was far less than its length (50 to 60) $\mathrm{mm}$, the kinetic energy and end corrections, respectively, were found to be negligible. The uncertainties in dynamic viscosities are of the order of $\pm 0.003 \mathrm{mPa} \cdot \mathrm{s}$.

The purity of the samples and accuracy of data were checked by comparing the measured densities and viscosities of the pure compounds with the literature values, which are given in Table 1 . Thus, our results are in good agreement with those listed in the literature.

\section{Results and Discussion}

Experimental values of densities $(\rho)$ and viscosities $(\eta)$ of mixtures at $298.15 \mathrm{~K}$ are listed as a function of mole fraction in Table 2 . The density values have been used to calculate excess molar volumes $\left(V^{E}\right)$ using the following equation:

$$
V_{m}^{E} / \mathrm{m}^{3} \cdot \mathrm{mol}^{-1}=\frac{\left(x_{1} M_{1}+x_{2} M_{2}\right)}{\rho_{12}}-\left(\frac{x_{1} M_{1}}{\rho_{1}}\right)-\left(\frac{x_{2} M_{2}}{\rho_{2}}\right),
$$

where $\rho_{12}$ is the densities of the mixture and $x_{1}, M_{1}, \rho_{1}$, and $x_{2}, M_{2}, \rho_{2}$ are the mole fractions, the molecular weights, and the densities of pure components 1 and 2, respectively.
TABLE 1: Comparison of experimental densities $(\rho)$, viscosities $(\eta)$, and speeds of sound $(u)$ of pure liquids with the literature values at $T=298.15 \mathrm{~K}$

\begin{tabular}{lcccc}
\hline \multirow{2}{*}{ Pure liquids } & \multicolumn{2}{c}{$\rho \times 10^{-3}\left(\mathrm{Kg} \mathrm{m}^{-3}\right)$} & \multicolumn{2}{c}{$\eta(\mathrm{mPa} \cdot \mathrm{s})$} \\
& Experimental & Literature & Experimental & Literature \\
\hline n-Octane & 0.69867 & $0.69866^{\mathrm{a}}$ & 0.512 & $0.515^{\mathrm{b}}$ \\
n-Decane & 0.72635 & $0.7267^{\mathrm{c}}$ & 0.845 & $0.861^{\mathrm{d}}$ \\
n-Dodecane & 0.74518 & $0.74172^{\mathrm{e}}$ & 1.336 & $1.332^{\mathrm{f}}$ \\
n-Tetradecane & 0.75913 & $0.75911^{\mathrm{g}}$ & 2.081 & $2.077^{\mathrm{g}}$ \\
Octan-2-ol & 0.81705 & $0.81708^{\mathrm{h}}$ & 6.429 & $6.435^{\mathrm{h}}$ \\
\hline${ }^{\mathrm{a}}[39],{ }^{\mathrm{b}}[37],{ }^{\mathrm{c}}[48],{ }^{\mathrm{d}}[42],{ }^{\mathrm{e}}[41],{ }^{\mathrm{f}}[38],{ }^{\mathrm{g}}[38],{ }^{\mathrm{h}}[6]$. & &
\end{tabular}

The variation in excess molar volumes, $V_{m}^{E}$ with mole fraction of the binary mixtures of n-octane, n-decane, ndodecane, and n-tetradecane with octan-2-ol at $T=298.15 \mathrm{~K}$, is displayed in Figure 1. The $V_{m}^{E}$ curve for the mixture of noctane and octan-2-ol is sigmoidal and tends to change to positive values at higher mole fractions $\left(x_{1} \geq 0.65\right)$ of $n$ octane while $V_{m}^{E}$ values for n-decane, n-dodecane, and ntetradecane with octan-2-ol mixtures show positive deviation over the entire composition range.

Generally, $V_{m}^{E}$ can be considered as arising from three types of interactions between component molecules of liquid mixtures [11-13]: (1) physical interactions consisting of mainly of dispersion forces or weak dipole-dipole interaction making a +ve contribution, hereby the contraction volume and compressibility of the mixtures, (2) chemical or specific interactions, which include charge transfer, forming of $\mathrm{H}$ bonds and other complex forming interactions, resulting in a -ve contribution, and (3) structural contribution due to differences in size and shape of the component molecules of the mixtures, due to fitting of component molecules into each other's structure, hereby reducing the volume and compressibility of the mixtures, resulting in a -ve contribution.

The large positive $V_{m}^{E}$ values (Figure 1) for n-decane, ndodecane, and n-tetradecane with octan-2-ol mixture are attributed to the breaking up of three-dimensional $\mathrm{H}$-bonded network of octan-2-ol due to the addition of solute, which is not compensated by the weak interactions between unlike molecules. The $V_{m}^{E}$ exhibits an inversion in sign in the mixtures $f$ (n-octane +2 -octanol). The values of $V_{m}^{E}$ are negative in the lower region of $x_{1}$ due to interstitial accommodation is more as compared to the de-clustering of 1-octanol molecules and beyond $\left(x_{1} \geq 0.65\right)$ as the amount of n-octane increases in the mixture, due to dispersion forces, thereby making a positive contribution to $V_{m}^{E}$.

The viscosity deviations $(\Delta \eta)$ were calculated using

$$
\Delta \eta / \mathrm{mPa} \cdot \mathrm{s}=\eta_{12}-x_{1} \eta_{1}-x_{2} \eta_{2}
$$

where $\eta_{12}$ is the viscosities of the mixture and $x_{1}, x_{2}$ and $\eta_{1}, \eta_{2}$ are the mole fraction and the viscosities of pure components 1 and 2 , respectively.

Figure 2 depicts the variation of $\Delta \eta$ with mole fraction of the binary mixtures of $n$-octane, $n$-decane, $n$-dodecane, and n-tetradecane with octan-2-ol at $T=298.15 \mathrm{~K}$. 


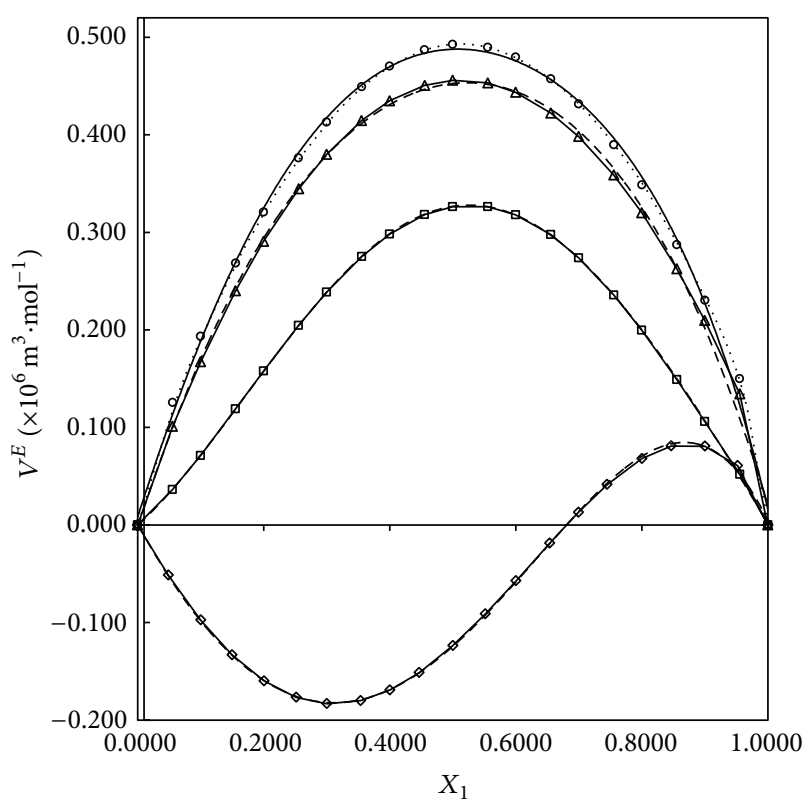

FIgURE 1: Plot of excess molar volumes $\left(V_{m}^{E}\right)$ against mole fraction of octan-2-ol with $(\diamond)$ n-octane; $(\square)$ n-decane; $(\triangle)$ n-dodecane, and n-tetradecane (O) at $T=298.15 \mathrm{~K}$. The corresponding dotted (- - ) curves have been derived from PFP theory.

The deviations viscosity may be generally explained by considering the following factors [14]. (1) The difference in size and shape of the component molecules and the loss of dipolar association to a decrease in viscosity; (2) specific interactions between unlike molecules such as $\mathrm{H}$-bond formation and charge transfer complexes may cause increase in viscosity in mixtures rather than in pure component. The former effect produces negative in excess viscosity, and latter effect produces positive in excess viscosity. Positive values of $\Delta \eta$ are indicative of strong interactions whereas negative values indicate weaker interactions [15].

The negative deviations in viscosity support the main factor of breaking of the self-associated alcohols and weak interactions between unlike molecules. The negative values viscosity deviation decreases in the following sequence: $\mathrm{n}$ octane $>$ n-decane $>$ n-dodecane $>$ n-tetradecane.

Excess Gibbs free energies of activation of viscous flow $\Delta G^{* E}$ for binary mixtures can be calculated as

$$
\Delta G^{* E}=R T\left[\ln \left(\frac{\eta v}{\eta_{2} v_{2}}\right)-x_{1} \ln \left(\frac{\eta_{1} v_{1}}{\eta_{2} v_{2}}\right)\right],
$$

where $v$ is the molar volume of the mixture, $v_{i}$ is the molar volume of the pure component, $R$ is the gas constant, $T$ is the absolute temperature, and $\eta$ is the dynamic viscosity of the mixture, respectively. $\eta_{i}$ is the dynamic viscosity of the pure component $i$ and $x_{1}$ the mole fraction in component. The $\Delta G^{* E}$ values of all binary systems are shown in Table 2 . The values of $\Delta G^{* E}$ for all binary mixtures are negative over entire mole fraction. According to Meyer et al. [16], negative values of $\Delta G^{* E}$ correspond to the existence of solute-solute association.

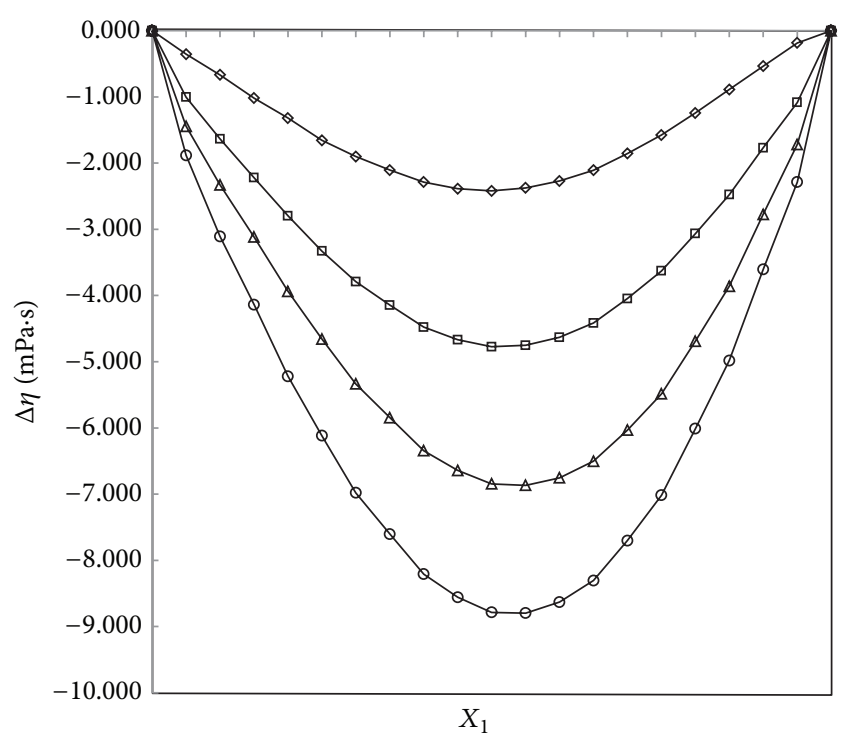

FIgURE 2: Plot of viscosity deviations $(\Delta \eta)$ against mole fraction of octan-2-ol with $(\diamond)$ n-octane; $(\square)$ n-decane; $(\triangle)$ n-dodecane and ntetradecane (o) at $T=298.15 \mathrm{~K}$.

The excess molar volumes and deviations in viscosity were fitted to Redlich and Kister [17] equation of the type

$$
Y=x_{1} x_{2} \sum_{i}^{n} a_{i}\left(x_{1}-x_{2}\right)^{i},
$$

where $Y$ is either $V^{E}$ or $\Delta \eta$ and $n$ is the degree of polynomial. Coefficient $a_{i}$ was obtained by fitting (5) to experimental results using a least-squares regression method. In each case, the optimum number of coefficients is ascertained from an examination of the variation in standard deviation $(\sigma)$.

$\sigma$ was calculated using the relation

$$
\sigma(Y)=\left[\frac{\sum\left(Y_{\text {expt }}-Y_{\text {calc }}\right)^{2}}{N-n}\right]^{1 / 2},
$$

where $N$ is the number of data points and $n$ is the number of coefficients. The calculated values of the coefficients $a_{i}$ along with the standard deviations $(\sigma)$ are given in Table 3 .

\section{Theoretical Analysis}

4.1. Semiempirical Models for Analyzing Viscosity of Liquid Mixtures. Several empirical and semiempirical relations have been used to represent the dependence of viscosity on concentration of components in binary liquid mixtures, and these are classified according to the number of adjustable parameters used to account for the deviation from some average $[18,19]$. We will consider here some of the most commonly used semiempirical models for analyzing viscosity of liquid mixtures based on one, two, and three parameters. An attempt has been made to check the suitability of equations for experimental data fits by taking into account the number of empirical adjustment coefficients. 
TAble 2: Densities $(\rho)$, viscosities $(\eta)$, excess molar volumes $V^{E}$, viscosities deviations $\Delta \eta$, and excess Gibbs free energy $\Delta G^{* E}$ of binary mixtures at $T=298.15 \mathrm{~K}$.

\begin{tabular}{|c|c|c|c|c|c|}
\hline$x_{1}$ & $\begin{array}{l}\rho \times 10^{-3} \\
\mathrm{~kg} \cdot \mathrm{m}^{-3}\end{array}$ & $\begin{array}{l}V_{m}^{E} \times 10^{6} \\
\mathrm{~m}^{3} \cdot \mathrm{mol}^{-1}\end{array}$ & $\begin{array}{c}\eta \\
\mathrm{mPa} \cdot \mathrm{s}\end{array}$ & $\begin{array}{c}\Delta \eta \\
\mathrm{mPa} \cdot \mathrm{s}\end{array}$ & $\begin{array}{c}\Delta G^{* E} \\
\mathrm{KJmol}^{-1}\end{array}$ \\
\hline \multicolumn{6}{|c|}{ n-Octane $(1)+$ octan-2-ol(2) } \\
\hline 0 & 0.81705 & 0 & 6.429 & 0 & 0 \\
\hline 0.0487 & 0.8114 & -0.051 & 5.956 & -0.185 & 115 \\
\hline 0.1002 & 0.8054 & -0.097 & 5.301 & -0.535 & 149 \\
\hline 0.1498 & 0.79959 & -0.133 & 4.654 & -0.888 & 137 \\
\hline 0.2006 & 0.79361 & -0.16 & 3.998 & -1.244 & 78 \\
\hline 0.2516 & 0.78756 & -0.177 & 3.364 & -1.576 & -30 \\
\hline 0.3003 & 0.78176 & -0.183 & 2.796 & -1.856 & -183 \\
\hline 0.3538 & 0.77534 & -0.18 & 2.228 & -2.108 & -410 \\
\hline 0.4003 & 0.76975 & -0.169 & 1.79 & -2.27 & -661 \\
\hline 0.4466 & 0.76415 & -0.151 & 1.411 & -2.375 & -960 \\
\hline 0.5001 & 0.75767 & -0.123 & 1.049 & -2.421 & -1359 \\
\hline 0.5517 & 0.75142 & -0.091 & 0.778 & -2.387 & -1776 \\
\hline 0.6002 & 0.74554 & -0.057 & 0.59 & -2.287 & -2157 \\
\hline 0.6539 & 0.73905 & -0.018 & 0.454 & -2.106 & -2469 \\
\hline 0.6994 & 0.73357 & 0.013 & 0.39 & -1.901 & -2560 \\
\hline 0.7449 & 0.72811 & 0.042 & 0.366 & -1.656 & -2431 \\
\hline 0.8 & 0.72157 & 0.068 & 0.376 & -1.32 & -2019 \\
\hline 0.8465 & 0.7161 & 0.081 & 0.402 & -1.018 & -1571 \\
\hline 0.9003 & 0.70985 & 0.081 & 0.434 & -0.668 & -1034 \\
\hline 0.9521 & 0.70394 & 0.061 & 0.441 & -0.355 & -670 \\
\hline 1 & 0.69867 & 0 & 0.512 & 0 & 0 \\
\hline \multicolumn{6}{|c|}{ n-Decane $(1)+$ octan-2-ol(2) } \\
\hline 0 & 0.81705 & 0 & 6.429 & 0 & 0 \\
\hline 0.0554 & 0.81077 & 0.036 & 5.222 & -0.898 & -233 \\
\hline 0.0998 & 0.80583 & 0.071 & 4.638 & -1.234 & -301 \\
\hline 0.1554 & 0.79974 & 0.119 & 3.972 & -1.589 & -403 \\
\hline 0.1999 & 0.79499 & 0.158 & 3.491 & -1.822 & -497 \\
\hline 0.2554 & 0.7892 & 0.205 & 2.951 & -2.052 & -632 \\
\hline 0.2999 & 0.78467 & 0.239 & 2.564 & -2.19 & -755 \\
\hline 0.3555 & 0.77916 & 0.275 & 2.136 & -2.308 & -927 \\
\hline 0.3998 & 0.7749 & 0.298 & 1.836 & -2.361 & -1078 \\
\hline 0.4554 & 0.76969 & 0.318 & 1.509 & -2.377 & -1285 \\
\hline 0.4999 & 0.76564 & 0.326 & 1.284 & -2.354 & -1461 \\
\hline 0.5555 & 0.76074 & 0.326 & 1.046 & -2.281 & -1690 \\
\hline 0.5998 & 0.75694 & 0.318 & 0.889 & -2.191 & -1871 \\
\hline 0.6555 & 0.7523 & 0.298 & 0.73 & -2.039 & -2080 \\
\hline 0.7 & 0.7487 & 0.274 & 0.63 & -1.89 & -2223 \\
\hline 0.7554 & 0.74432 & 0.236 & 0.538 & -1.673 & -2337 \\
\hline 0.7998 & 0.74091 & 0.2 & 0.487 & -1.476 & -2362 \\
\hline 0.8554 & 0.73674 & 0.149 & 0.45 & -1.203 & -2281 \\
\hline 0.8999 & 0.73347 & 0.106 & 0.438 & -0.966 & -2126 \\
\hline 0.9554 & 0.72948 & 0.052 & 0.445 & -0.649 & -1811 \\
\hline 1 & 0.72635 & 0 & 0.845 & 0 & 0 \\
\hline \multicolumn{6}{|c|}{ n-Dodecane(1) + octan-2-ol(2) } \\
\hline 0 & 0.81705 & 0 & 6.429 & 0 & 0 \\
\hline 0.0554 & 0.81098 & 0.101 & 5.513 & -0.634 & -159 \\
\hline 0.0999 & 0.80637 & 0.167 & 4.916 & -1.004 & -296 \\
\hline 0.1554 & 0.80091 & 0.24 & 4.254 & -1.383 & -404 \\
\hline
\end{tabular}


TABLe 2: Continued.

\begin{tabular}{|c|c|c|c|c|c|}
\hline$x_{1}$ & $\begin{array}{l}\rho \times 10^{-3} \\
\mathrm{~kg} \cdot \mathrm{m}^{-3}\end{array}$ & $\begin{array}{l}V_{m}^{E} \times 10^{6} \\
\mathrm{~m}^{3} \cdot \mathrm{mol}^{-1}\end{array}$ & $\begin{array}{c}\eta \\
\mathrm{mPa} \cdot \mathrm{s}\end{array}$ & $\begin{array}{c}\Delta \eta \\
\mathrm{mPa} \cdot \mathrm{s}\end{array}$ & $\begin{array}{c}\Delta G^{* E} \\
\mathrm{KJmol}^{-1}\end{array}$ \\
\hline 0.1998 & 0.79676 & 0.291 & 3.786 & -1.625 & -517 \\
\hline 0.2555 & 0.7918 & 0.345 & 3.272 & -1.856 & -659 \\
\hline 0.2998 & 0.78805 & 0.38 & 2.916 & -1.986 & -770 \\
\hline 0.3554 & 0.78355 & 0.415 & 2.532 & -2.087 & -902 \\
\hline 0.3998 & 0.78012 & 0.435 & 2.27 & -2.123 & -999 \\
\hline 0.4554 & 0.77603 & 0.451 & 1.995 & -2.115 & -1102 \\
\hline 0.4999 & 0.7729 & 0.456 & 1.813 & -2.071 & -1167 \\
\hline 0.5555 & 0.76916 & 0.453 & 1.627 & -1.973 & -1219 \\
\hline 0.5998 & 0.76631 & 0.444 & 1.508 & -1.866 & -1236 \\
\hline 0.6555 & 0.76288 & 0.422 & 1.391 & -1.699 & -1221 \\
\hline 0.6998 & 0.76027 & 0.398 & 1.32 & -1.545 & -1180 \\
\hline 0.7554 & 0.75713 & 0.359 & 1.253 & -1.328 & -1095 \\
\hline 0.7998 & 0.75473 & 0.32 & 1.213 & -1.142 & -1005 \\
\hline 0.8555 & 0.75185 & 0.263 & 1.176 & -0.896 & -869 \\
\hline 0.8999 & 0.74965 & 0.21 & 1.152 & -0.694 & -750 \\
\hline 0.9555 & 0.747 & 0.134 & 1.124 & -0.439 & -599 \\
\hline 0.9997 & 0.74519 & 0 & 1.337 & 0 & 0 \\
\hline \multicolumn{6}{|c|}{ n-Tetradecane(1) + octan-2-ol(2) } \\
\hline 0 & 0.81705 & 0 & 6.429 & 0 & 0 \\
\hline 0.0555 & 0.81134 & 0.126 & 5.619 & -0.568 & -144 \\
\hline 0.0999 & 0.80721 & 0.193 & 5.163 & -0.831 & -230 \\
\hline 0.1555 & 0.80239 & 0.268 & 4.632 & -1.121 & -330 \\
\hline 0.1998 & 0.7988 & 0.321 & 4.238 & -1.321 & -417 \\
\hline 0.2554 & 0.79459 & 0.376 & 3.786 & -1.533 & -531 \\
\hline 0.2998 & 0.79144 & 0.413 & 3.455 & -1.67 & -628 \\
\hline 0.3555 & 0.78774 & 0.449 & 3.081 & -1.802 & -751 \\
\hline 0.3999 & 0.78496 & 0.47 & 2.813 & -1.876 & -850 \\
\hline 0.4554 & 0.78171 & 0.487 & 2.519 & -1.93 & -968 \\
\hline 0.4999 & 0.77925 & 0.492 & 2.314 & -1.941 & -1054 \\
\hline 0.5555 & 0.77637 & 0.49 & 2.098 & -1.915 & -1144 \\
\hline 0.5998 & 0.7742 & 0.48 & 1.957 & -1.863 & -1196 \\
\hline 0.6554 & 0.77163 & 0.457 & 1.82 & -1.759 & -1226 \\
\hline 0.7 & 0.76969 & 0.432 & 1.741 & -1.644 & -1217 \\
\hline 0.7555 & 0.76741 & 0.39 & 1.683 & -1.46 & -1154 \\
\hline 0.8 & 0.76569 & 0.348 & 1.668 & -1.282 & -1060 \\
\hline 0.8555 & 0.76365 & 0.287 & 1.688 & -1.02 & -887 \\
\hline 0.9 & 0.76211 & 0.23 & 1.736 & -0.779 & -703 \\
\hline 0.9553 & 0.76029 & 0.15 & 1.835 & -0.439 & -424 \\
\hline 0.9997 & 0.75914 & 0 & 2.081 & 0 & 0 \\
\hline
\end{tabular}

The equation of Grunberg-Nissan, Tamara and Kurata Hind et al., and Katti and Chaudhri has one adjustable parameter.

Gruenberg-Nissan provided the following empirical equation containing one adjustable parameter [20]. The equation is

$$
\ln \eta_{12}=x_{1} \ln \eta_{1}+x_{2} \ln \eta_{2}+x_{1} x_{2} G_{12}
$$

where $G_{12}$ may be regarded as a parameter proportional to the interchange energy also an approximate measure of the strength of the interaction between the components.

The one-parameter equation due to Tamura and Kurata [21] gave the equation of the form

$$
\eta_{m}=x_{1} \eta_{1} \Phi+x_{2} \eta_{2} \Phi_{2}+2\left(x_{1} x_{2} \Phi \Phi_{2}\right)^{1 / 2} T_{12},
$$

where $\Phi$ and $\Phi_{2}$ are the volume fractions of components 1 and 2, respectively; $T_{12}$ is Tamura and Kurata constant. 
TABLE 3: Coefficients $a_{i}$ of (4) and corresponding standard deviation $(\sigma)$ of $(5)$ at $T=298.15 \mathrm{~K}$.

\begin{tabular}{lccccc}
\hline System & $a_{0}$ & $a_{1}$ & $a_{2}$ & $a_{3}$ & $\sigma$ \\
\hline \multicolumn{7}{c}{$\mathrm{n}$-Octane + octan-2-ol } \\
$V_{m}^{E} \times 10^{6} /\left(\mathrm{m}^{3} \cdot \mathrm{mol}^{-1}\right)$ & 0.125 & 0.1577 & -0.41 & 0.1523 & 0.943 \\
$\Delta \eta /(\mathrm{mPa} \cdot \mathrm{s})$ & -9.6807 & 0.4921 & 4.661 & -2.7989 & 0.024 \\
\hline \multicolumn{7}{c}{ n-Decane + octan-2-ol } \\
$V_{m}^{E} \times 10^{6} /\left(\mathrm{m}^{3} \cdot \mathrm{mol}^{-1}\right)$ & 0.129 & 0.167 & -0.462 & 0.1437 & 0.0023 \\
$\Delta \eta /(\mathrm{mPa} \cdot \mathrm{s})$ & -8.4704 & 2.213 & -6.8274 & -1.0134 & 0.1273 \\
\hline \multicolumn{7}{c}{ n-Dodecane +octan-2-ol } \\
$V_{m}^{E} \times 10^{6} /\left(\mathrm{m}^{3} \cdot \mathrm{mol}^{-1}\right)$ & 0.363 & -1.276 & 0.289 & 0.812 & 0.529 \\
$\Delta \eta /(\mathrm{mPa} \cdot \mathrm{s})$ & -7.989 & 3.365 & -2.905 & 8.812 & 0.060 \\
\hline \multicolumn{7}{c}{$\mathrm{n}$-Tetradecane +octan-2-ol } \\
$V_{m}^{E} \times 10^{6} /\left(\mathrm{m}^{3} \cdot \mathrm{mol}^{-1}\right)$ & 0.880 & -0.116 & 0.009 & 0.708 & 0.020 \\
$\Delta \eta /(\mathrm{mPa} \cdot \mathrm{s})$ & -6.322 & -4.730 & -10.25 & 15.66 & 0.377 \\
\hline
\end{tabular}

Hind et al. [22] proposed the following equation:

$$
\eta_{m}=x_{1}^{2} \eta_{1}+x_{2}^{2} \eta_{2}+2 x_{1} x_{2} H_{12}
$$

where $H_{12}$ is attributed to unlike pair interactions.

Katti and Chaudhri [23] derived the following equation

$$
\ln \eta V=x_{1} \ln \eta V_{1}^{0}+x_{2} \ln \eta V_{2}^{0}+\frac{x_{1} x_{2} W_{\text {vis }}}{R T},
$$

where $W_{\text {vis }}$ is an interaction term and $v_{i}$ is the molar volume of pure component $i$.

Heric [24] expression is

$$
\begin{aligned}
\ln \eta_{m}= & x_{1} \ln \eta_{1}+x_{2} \ln \eta_{2}+x_{1} \ln \eta_{1} \\
& +x_{2} \ln \eta_{2}+\ln \left(x_{1} \eta_{1}+x_{2} \eta_{2}\right)+\delta_{12},
\end{aligned}
$$

where $\delta_{12}=\alpha_{12} x_{1} x_{2}$ is a term representing departure from a noninteracting system and $\alpha_{12}=\alpha_{21}$ is the interaction parameter. Either $\alpha_{12}$ or $\alpha_{21}$ can be expressed as a linear function of composition:

$$
\alpha_{12}=\beta_{12}^{\prime}+\beta_{12}^{\prime \prime}\left(x_{1}-x_{2}\right) .
$$

From an initial guess of the values of coefficients $\beta_{12}^{\prime}$ and $\beta_{12}^{\prime \prime}$, the values of $\alpha_{12}$ are computed.

Heric and Brewer [25] equation is

$$
\begin{aligned}
\ln v= & x_{1} \ln v_{1}+x_{2} \ln v_{2}+x_{1} \ln M_{1}+x_{2} \ln M_{2} \\
& -\ln \left[x_{1} M_{1}+x_{2} M_{2}\right]+x_{1} x_{2}\left[\alpha_{12}+\alpha_{21}\left(x_{1}-x_{2}\right)\right] .
\end{aligned}
$$

$M_{1}$ and $M_{2}$ are molecular weights of components 1 and 2 , and $\alpha_{12}$ and $\alpha_{21}$ are interaction parameters, and other terms involved have their usual meaning. $\alpha_{12}$ and $\alpha_{21}$ are parameters, which can be calculated from the least-squares method.

McAllister's multibody interaction model [26] was widely used to correlate kinematic viscosity $(\nu)$ data. The twoparameter McAllister equation based on Eyring's [27] theory of absolute reaction rates has taken into account interaction of both like and unlike molecules by two-dimensional threebody model. The three-body interaction model is

$$
\begin{aligned}
\ln v_{m}= & x_{1}^{3} \ln v_{1}+3 x_{1}^{2} x_{2} \ln Z_{12}+3 x_{1} x_{2}^{2} \ln Z_{21} \\
& +x_{2}^{3} \ln v_{2}-\ln \left[x_{1}+\frac{\left(x_{2} M_{2}\right)}{M_{1}}\right] \\
& +3 x_{1}^{2} x_{2} \ln \left[\frac{2}{3}+\frac{M_{2}}{\left(3 M_{1}\right)}\right] \\
& +3 x_{1} x_{2}^{2} \ln \left[\frac{1}{3}+\frac{2 M_{2}}{\left(3 M_{1}\right)}\right] x_{2}^{3} \ln \left(\frac{M_{2}}{M_{1}}\right) .
\end{aligned}
$$

And four-body model was given by

$$
\begin{aligned}
\ln v_{m}= & x_{1}^{4} \ln v_{1}+4 x_{1}^{3} x_{2} \ln Z_{1112} \\
& +6 x_{1}^{2} x_{2}^{2} \ln Z_{1122}+4 x_{1} x_{2}^{3} \ln Z_{2221}+x_{2}^{4} \ln v_{2} \\
& -\ln \left[x_{1}+x_{2}\left(\frac{M_{2}}{M_{1}}\right)\right] \\
& +4 x_{1}^{3} x_{2} \ln \left[3+\frac{\left(M_{2} / M_{1}\right)}{4}\right] \\
& +6 x_{1}^{2} x_{2}^{2} \ln \left[1+\frac{\left(M_{2} / M_{1}\right)}{2}\right] \\
& +4 x_{1} x_{2}^{3} \ln \left[1+\frac{\left(3 M_{2} / M_{1}\right)}{4}\right]+x_{2}^{4} \ln \left(\frac{M_{2}}{M_{1}}\right),
\end{aligned}
$$

where $Z_{12}, Z_{21}, Z_{1112}, Z_{1122}$, and $Z_{2221}$ are interaction parameters and $M_{i}$ and $\nu_{i}$ are the molecular mass and kinematic viscosity of pure component $i$, respectively.

The correlating ability of each of (6)-(14) was tested as well as their adjustable parameters and standard deviations $(\sigma)$ :

$$
\begin{aligned}
& \sigma(\%) \\
& =\left[\left(\frac{1}{(n-k)} \sum \frac{100\left(\eta_{\text {exptl }}-\eta_{\text {calcd }}\right)}{\eta_{\text {exptl }}}\right)^{2}\right]^{1 / 2},
\end{aligned}
$$

where $n$ represents the number of data points and $k$ is the number of numerical coefficients given in Table 4. The interaction parameter $G_{12}$ is negative for binary systems. Nigam and Mahl [28] concluded from the study of binary mixtures that (1) if $\Delta \eta>0, G_{12}>0$ and magnitude of both are large then strong specific interaction would be present; (2) if $\Delta \eta<0, G_{12}>0$ then weak specific interaction would be present; (3) if $\Delta \eta<0, G_{12}<0$ magnitude of both are large then the dispersion force would be dominant. According to Fort and Moore [29] and Ramamoorty and Varadachari [30], system exhibits strong interaction if the $G_{12}$ is positive; if it is negative they show weak interaction. On this basis, we can say that there is a weak interaction in the system studied.

Interaction parameter $W_{\text {vis }}$ shows almost the same trend as that of $G_{12}$. In fact, one could say that the parameters 
TABLE 4: Adjustable parameters of (6)-(13) and standard deviations of binary mixture viscosities for $x_{1}$ n-alkanes $+\left(1-x_{1}\right)$ octan-2-ol at $T=298.15 \mathrm{~K}$.

\begin{tabular}{|c|c|c|c|c|}
\hline \multirow{2}{*}{ Equation } & \multicolumn{4}{|c|}{ System including n-alkanes + octan-2-ol } \\
\hline & n-Octane & n-Decane & n-Dodecane & n-Tetradecane \\
\hline \multicolumn{5}{|c|}{ Grunberg-Nissan } \\
\hline$G_{12}$ & -2.398 & -3.226 & -1.997 & -2.002 \\
\hline$\sigma$ & 3.759 & 3.904 & 0.858 & 1.075 \\
\hline \multicolumn{5}{|c|}{ Tamura and Kurata } \\
\hline$T_{12}$ & 0.872 & -1.117 & 0.184 & 0.675 \\
\hline$\sigma$ & 1.737 & 1.884 & 0.812 & 0.782 \\
\hline \multicolumn{5}{|c|}{ Hind et al. } \\
\hline$H_{12}$ & -0.91 & -1.409 & -0.401 & 0.079 \\
\hline$\sigma$ & 1.758 & 2.145 & 1.172 & 0.711 \\
\hline \multicolumn{5}{|c|}{ Katti and Chaudhri } \\
\hline$W_{\text {vis }}$ & -2.402 & -3.198 & -1.96 & -1.871 \\
\hline$\sigma$ & 3.755 & 3.905 & 0.857 & 1.081 \\
\hline \multicolumn{5}{|c|}{ Heric and Brewer } \\
\hline$\alpha_{12}$ & -2.381 & -3.936 & -2.109 & -2.104 \\
\hline$\alpha_{21}$ & -4.123 & -5.529 & -1.506 & -0.827 \\
\hline$\sigma$ & -0.926 & 2.449 & -0.559 & 0.866 \\
\hline \multicolumn{5}{|c|}{ McAllister's three-body } \\
\hline$Z_{12}$ & 0.185 & 0.094 & 0.879 & 1.439 \\
\hline$Z_{21}$ & 6.363 & 7.068 & 3.929 & 3.544 \\
\hline$\sigma$ & 0.926 & 2.449 & 0.559 & 0.866 \\
\hline \multicolumn{5}{|c|}{ McAllister's four-body } \\
\hline$Z_{1112}$ & 0.269 & 0.51 & 0.817 & 1.140 \\
\hline$Z_{1122}$ & 0.936 & 19.584 & 3.639 & 7.334 \\
\hline$Z_{2221}$ & 6.926 & 1.998 & 3.598 & 2.871 \\
\hline$\sigma$ & 5.149 & 5.865 & 0.622 & 1.622 \\
\hline
\end{tabular}

$G_{12}$ and $W_{\text {vis }}$ exhibit almost similar behaviour, which is not unlikely in view of logarithmic nature of both equations.

Tamara and Kurata and Hind et al. represent the binary mixture satisfactory as compared to Gruenberg-Nissan and Katti and Chaudhri. Use of three parameters equation reduces the $\sigma$ values significantly below that of two parameters equation. From this study, it can be concluded that the correlating ability significantly improves for these nonideal systems as number of adjustable parameters is increased. From Table 4, it is clear that McAllister's three-body interaction model is suitable for correlating the kinematic viscosities of the binary mixtures studied.

4.2. Prigogine-Flory-Patterson (PFP) Theory. The PrigogineFlory-Patterson (PFP) theory [31-34] has been commonly employed to estimate and analyze excess thermodynamic functions theoretically. This theory has been described in details by Patterson and coworkers [35, 36]. According to PFP theory, $V_{m}^{E}$ can be separated into three factors: (1) an interactional contribution, $V_{m}^{E}$ (int.) (2) a free volume contribution,
$V_{m}^{E}(\mathrm{fv})$, and (3) an internal pressure contribution, $V_{m}^{E}\left(P^{*}\right)$. The expression for these three contributions are given as $V_{m}^{E}$ :

$$
\begin{gathered}
V_{m}^{E}(\text { int })=\left[\frac{\left(v^{1 / 3}-1\right) v^{2 / 3} \psi_{1} \theta_{2}}{\left(4 / 3 v^{-1 / 3}-1\right) P_{1}^{*} \chi_{12}}\right], \\
V_{m}^{E}(\mathrm{fv})=\frac{\left[\left(v_{1}-v_{2}\right)^{2}\left(14 / 9 v^{-1 / 3}-1\right) \psi_{1} \psi_{2}\right]}{\left[\left(14 / 9 v^{-1 / 3}-1\right) v\right]}, \\
V_{m}^{E}\left(P^{*}\right)=\frac{\left[\left(v_{1}-v_{2}\right)\left(P_{1}^{*}+P_{2}^{*}\right) \psi_{1} \psi_{2}\right]}{\left(P_{1}^{*} \psi_{1}+P_{2}^{*} \psi_{2}\right)} .
\end{gathered}
$$

Thus, the excess molar volume $V_{m}^{E}$ is given as

$$
\frac{V_{m}^{E}}{\left(x_{1} V_{1}+x_{2} V_{2}\right)}=V_{m}^{E}(\text { int })-V_{m}^{E}(\mathrm{fv})+V_{m}^{E}\left(P^{*}\right)
$$

where $\psi, \theta$, and $P^{*}$ represent the contact energy fraction, surface site fraction, and characteristic pressure, respectively, and are calculated as

$$
\begin{gathered}
\psi_{1}=\left(1-\psi_{2}\right)=\frac{\Phi_{1} P_{1}^{*}}{\left(\Phi_{1} P_{1}^{*}+\Phi_{2} P_{2}^{*}\right)}, \\
\theta_{2}=\left(1-\theta_{1}\right)=\frac{\Phi_{2}}{\left[\Phi_{1}\left(V_{2}^{*} / V_{1}^{*}\right)\right]}, \\
P^{*}=\frac{T v^{2} \alpha}{\kappa_{T}} .
\end{gathered}
$$

The details of the notations and terms used in (16)-(19) may be obtained from the literature [31-34, 37, 38]. The other parameters pertaining to pure liquids and the mixtures are obtained from the Flory theory $[7,31,38]$ while $\alpha$ and $\kappa_{T}$ values are taken from the literature [39-44]. The interaction parameter $\chi_{12}$ required for the calculation of $V_{m}^{E}$ using PFP theory has been derived by fitting the $V_{m}^{E}$ expression to the experimental equimolar value of $V_{m}^{E}$ for each system under study.

The values of $\chi_{12}, \theta_{2}$, three PFP contributions interactional, free volume, $P^{*}$ effect, and experimental and calculated (using PFP theory) $V_{m}^{E}$ values at near equimolar composition are presented in Table 5. Study of the data presented in Table 6 reveals that the interactional and free volume contributions are positive, whereas $P^{*}$ contributions are negative for all the three systems under investigation. For these binary mixtures, it is only the interactional contribution which dominates over the remaining two contributions. The $P^{*}$ contribution, which depends both on the differences of internal pressures and differences of reduced volumes of the components, has little significance for the studied binary mixtures as compared to the other two.

Furthermore, in order to check whether $\chi_{12}$, derived from nearly equimolar $V_{m}^{E}$ values, can predict the correct composition dependence, $V_{m}^{E}$ has been calculated theoretically using $\chi_{12}$ over the entire composition range. The theoretically calculated values are plotted in Figure 1 for comparison with the experimental results. Figure 1 show that the PFP theory is 
TABLE 5: Flory parameters of the pure compounds.

\begin{tabular}{lccc}
\hline Components & $10^{6} \mathrm{~V}^{*} /\left(\mathrm{m}^{3} \cdot \mathrm{mol}^{-1}\right)$ & $10^{6} \mathrm{P}^{*}\left(\mathrm{~J} \cdot \mathrm{m}^{-3}\right)$ & $T^{*} / \mathrm{K}$ \\
\hline Octan-2-ol & 129.9790 & 535 & 5563 \\
n-Octane & 127.4844 & 444 & 4826 \\
n-Decane & 155.6091 & 453 & 5091 \\
n-Dodecane & 183.7700 & 455 & 5290 \\
n-Tetradecane & 212.1200 & 460 & 5479 \\
\hline
\end{tabular}

quite successful in predicting the trend of the dependence of $V_{m}^{E}$ on composition for the present systems.

In order to perform a numerical comparison of the estimation capability of the PFP theory, we calculated the standard percentage deviations $(\sigma \%)$ using the relation

$$
\sigma \%=\left[\sum\left\{\frac{100(\text { expt }- \text { theor. })}{\operatorname{expt}}\right\}^{2}(n-1)\right]^{1 / 2},
$$

where $n$ represents the number of experimental data points.

4.3. Bloomfield and Dewan Model. There are different expressions available in the literature to calculate $\eta$. Here, Bloomfield and Dewan [45] model have been applied to compare calculated $\Delta \ln \eta$ values using experimental data for each binary mixture by the following relation:

$$
\Delta \ln \eta=\ln \eta-\left(x_{1} \ln \eta_{1}+x_{2} \ln \eta_{2}\right) .
$$

Bloomfield and Dewan [45] developed the expression from the combination of the theories of free volumes and absolute reaction rate

$$
\Delta \ln \eta=f(v)-\frac{\Delta G^{R}}{R T}
$$

where $f(v)$ is the characteristic function of the free volume defined by

$$
f(v)=\frac{1 /(v-1) x_{1}}{\left(v_{1}-1\right)}-\frac{x_{2}}{v_{2}-1}
$$

and $\Delta G^{R}$ is the residual energy of mixing, calculated with the following expression [46]:

$$
\Delta G^{R}=\Delta G^{E}+R T\left\{x_{1} \ln \left(\frac{x_{1}}{\Phi_{1}}\right)+x_{2} \ln \left(\frac{x_{2}}{\Phi_{2}}\right)\right\},
$$

where $\Phi_{1}$ and $\Phi_{2}$ are segment fractions defined by

$$
\Phi_{2}=1-\Phi_{1}=\frac{x_{2}}{\left[x_{2}+x_{1}\left(r_{1} / r_{2}\right)\right]},
$$

where $r_{1}$ and $r_{2}$ are in the ratio of respective molar core volumes $V_{1}^{*}$ and $V_{2}^{*}$.
The excess energy can be obtained from the statistical theory of liquid mixtures proposed by Flory and coworkers $[31,32]$ and is given by

$$
\begin{aligned}
\Delta G^{E}= & x_{1} P_{1}^{*} V_{1}^{*}\left[\frac{1}{\left(v_{1}\right)}-\frac{1}{(v)}\right] \\
& +3 \widetilde{T}_{1} \ln \left\{\frac{\left(v_{1}^{1 / 3}-1\right)}{\left(v^{1 / 3}-1\right)}\right\} \\
& +x_{2} P_{2}^{*} V_{2}^{*}\left[\frac{1}{\left(v_{2}\right)}-\frac{1}{(v)}\right] \\
& +\left[3 \widetilde{T}_{2} \ln \left\{\frac{\left(v_{2}^{1 / 3}-1\right)}{\left(v^{1 / 3}-1\right)}\right\}\right] \\
& +\frac{\left(x_{1} \theta_{2} V_{1}^{*} \chi_{12}\right)}{v},
\end{aligned}
$$

where the various symbols used have their usual meanings.

Using the $\chi_{12}$ values from fitting values of $V_{m}^{E}$ and the values of the parameters for the pure liquid components, we have calculated $\Delta G^{R}$ and $f(v)$ and finally $\Delta \ln \eta$, according to the Bloomfield and Dewan relationship, which is compared with the experimental data. Figure 3 shows that the good agreement between the estimated and experimental curves occurs for given binary systems.

4.4. Jouyban and Acree Model. Hasan et al. $[6,47,48]$ has used this model for various binary system proposed a model for correlating the density and viscosity of liquid mixtures at various temperatures. The proposed equation is

$$
\begin{aligned}
\ln y_{m, T}= & f_{1} \ln y_{1, T} \\
& +f_{2} \ln y_{2, T}+f_{1} f_{2} \sum\left[\frac{A_{j}\left(f_{1}-f_{2}\right)^{j}}{T}\right],
\end{aligned}
$$

where $y_{m, T}, y_{1, T}$, and $y_{2, T}$ is density or viscosity of the mixture and solvents 1 and 2 at temperature $T$, respectively, $f_{1}$ and $f_{2}$ are the volume fractions of solvents in case of density and mole fraction in case of viscosity, and $A_{j}$ are the model constants.

The correlating ability of the Jouyban-Acree model was tested by calculating the average percentage deviation (APD) between the experimental and calculated density and viscosity as

$$
\mathrm{APD}=\left(\frac{100}{N}\right) \sum\left[\frac{\left(\left|y_{\text {exptl }}-y_{\text {calcd }}\right|\right)}{y_{\text {exptl }}}\right],
$$

where $N$ is the number of data points in each set. The optimum numbers of constants $A_{j}$, in each case, were determined from the examination of the average percentage deviation value. 
TABLE 6: Calculated values of the three contributions to the excess molar volume from the PFP theory with interaction parameter $T=298.15 \mathrm{~K}$.

\begin{tabular}{lcccccc}
\hline Component & \multirow{2}{*}{$\chi_{12} \times 10^{6}\left(\mathrm{~J} \cdot \mathrm{m}^{-3}\right)$} & \multicolumn{2}{c}{$V^{E} \times 10^{6}\left(\mathrm{~m}^{3} \cdot \mathrm{mol}^{-1}\right)$} & at $x=0.5$ & \multicolumn{3}{c}{ Calculated contribution } \\
& & Experimental & PEP & $V^{E} \times 10^{6}(\mathrm{int})$ & $V^{E} \times 10^{6}(\mathrm{fv})$ & $V^{E} \times 10^{6}\left(P^{*}\right)$ \\
\hline n-Octane + octan-2-ol & 11.59 & 0.123 & 0.124 & 0.0331 & 0.1087 \\
n-Decane + octan-2-ol & 12.57 & 0.326 & 0.328 & 0.5999 & 0.0644 & -0.4194 \\
n-Dodecane + octan-2-ol & 16.57 & 0.456 & 0.458 & 0.5524 & 0.0175 & -0.0666 \\
n-Ttetradecane + octan-2-ol & 15.08 & 0.492 & 0.494 & 0.5157 & 0.0116 \\
\hline
\end{tabular}

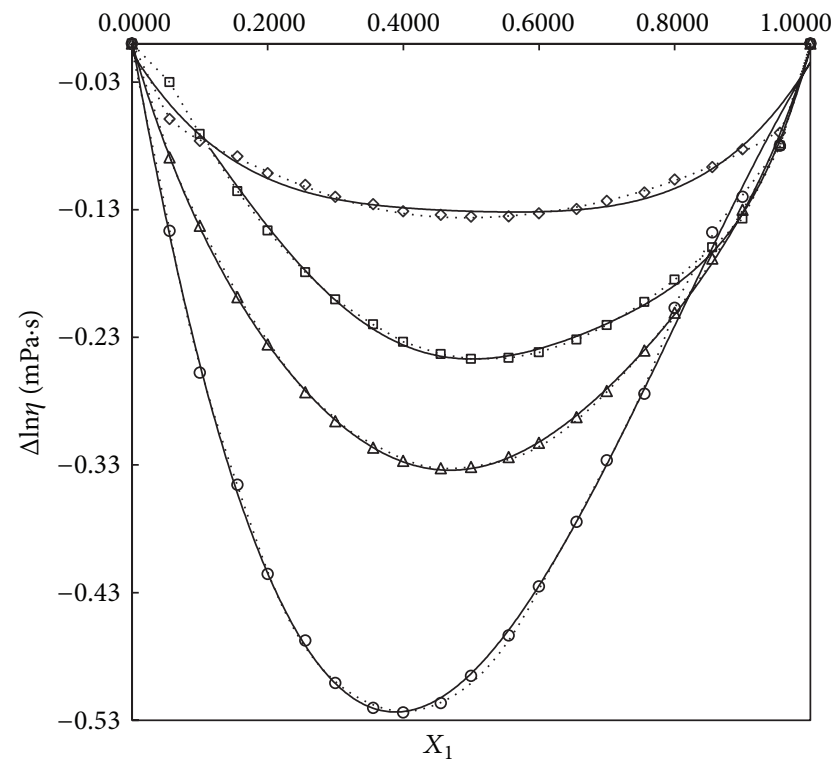

FIGURE 3: Plot of $\Delta \ln \eta$ against mole fraction of octan-2-ol with $(\diamond)$ n-octane; $(\square)$ n-decane; $(\triangle)$ n-dodecane, and n-tetradecane (o) at $T$ $=298.15 \mathrm{~K}$. The corresponding dotted (- - ) curves have been derived from Bloomfield and Dewan model.

The constants $A_{j}$ calculated from the least square analysis are presented in Table 7 along with the average percentage deviation (APD). The proposed model provides reasonably accurate calculations for the density, viscosity, and ultrasonic velocity of binary liquid mixtures at $298.15 \mathrm{~K}$, and the model could be used in data modeling.

\section{Conclusions}

The present paper is a continuing effort towards the understanding of the mixing behavior of binary liquid mixtures comprising of n-alkanes + octan-2-ol. Excess molar volumes and deviations in viscosity were calculated and fitted to the Redlich-Kister equation to test the quality of the experimental values. The negative deviations in viscosity support the main factor of breaking of the self-associated alcohols and weak interactions between unlike molecules. Several empirical and semiempirical relations have been used to represent the dependence of viscosity on concentration of components in binary liquid mixtures. An attempt has been made to check the suitability of empirical and semiempirical relations for experimental viscosities data of $n$-alkanes + octan-2ol fits by taking into account the number of empirical
TABLE 7: Parameters of Jouyban-Acree model and average percentage deviation for densities, viscosities, and ultrasonic velocities at of binary mixtures at $T=298.15 \mathrm{~K}$.

\begin{tabular}{lcccc}
\hline System & $A_{0}$ & $A_{1}$ & $A_{2}$ & APD \\
\hline Density & & & & \\
n-Octane + octan-2-ol & 3.7446 & -1.8027 & 0.616 & 0.0293 \\
n-Decane + octan-2-ol & -9.0926 & 1.0266 & 0.6448 & 0.1183 \\
n-Dodecane + octan-2-ol & -11.8504 & 0.0401 & 0.4771 & 0.0816 \\
n-Tetradecane + octan-2-ol & -12.6833 & 3.5123 & -4.3389 & 0.0559 \\
\hline Viscosity & & & & \\
n-Octane + octan-2-ol & -7.1847 & -6.9259 & 3.3215 & 0.1423 \\
n-Decane + octan-2-ol & -4.2926 & 11.2857 & -2.7614 & 0.7668 \\
n-Dodecane + octan-2-ol & -7.5692 & -10.9008 & 4.4397 & 0.1031 \\
n-Tetradecane + octan-2-ol & -6.4032 & -26.9478 & -7.7829 & 0.4296 \\
\hline
\end{tabular}

adjustment coefficients. Bloomfield and Dewan model and McAllister's three-body interaction model are suitable for the above binary system. PFP theory is also quite successful in predicting the trend of the dependence of $V_{m}^{E}$ on composition for the present systems.

\section{Acknowledgments}

Authors are thankful to Prof B. R. Arbad, Dr. B. A. M. university for their valuable suggestions and discussion. Authors are also thankful to Principal Dr. R. S. Agarwal, J. E. S. College, Jalna for the facilities provided.

\section{References}

[1] K. Lal, N. Tripathi, and G. P. Dubey, "Densities, viscosities, and refractive indices of binary liquid mixtures of hexane, decane, hexadecane, and squalane with benzene at $298.15 \mathrm{~K}$," Journal of Chemical and Engineering Data, vol. 45, no. 5, pp. 961-964, 2000.

[2] J. A. Estrada-Baltazar, F. J. Juan, and A. Gustavo, "Experimental liquid viscosities of decane and octane + decane from $298.15 \mathrm{~K}$ to $373.15 \mathrm{~K}$ and up to $25 \mathrm{MPa}$," Journal of Chemical and Engineering Data, vol. 43, no. 3, pp. 441-446, 1998.

[3] Y. Zhang, R. M. Venable, and R. W. Pastor, "Molecular dynamics simulations of neat alkanes: the viscosity dependence of rotational relaxation," Journal of Physical Chemistry, vol. 100, no. 7, pp. 2652-2660, 1996.

[4] T. M. Aminabhavi, M. I. Aralaguppi, B. Gopalakrishna, and R. S. Khinnavar, "Densities, shear viscosities, refractive indices, and speeds of sound of bis(2-methoxyethyl) ether with hexane, heptane, octane, and 2,2,4-trimethylpentane in the temperature 
interval 298.15-318.15 K," Journal of Chemical and Engineering Data, vol. 39, no. 3, pp. 522-528, 1994.

[5] D. Gómez-Díz, J. C. Mejuto, J. M. Navaza, and A. RodríguezÁlvarez, "Viscosities, densities, surface tensions, and refractive indexes of 2,2,4-trimethylpentane + cyclohexane + decane ternary liquid systems at $298.15 \mathrm{~K}$," Journal of Chemical and Engineering Data, vol. 47, no. 4, pp. 872-875, 2002.

[6] M. Hasan, D. F. Shirude, A. P. Hiray, A. B. Sawant, and U. B. Kadam, "Densities, viscosities and ultrasonic velocities of binary mixtures of methylbenzene with hexan-2-ol, heptan2-ol and octan-2-ol at T=298.15 and 308.15 K," Fluid Phase Equilibria, vol. 252, no. 1-2, pp. 88-95, 2007.

[7] H. Iloukhani, B. Samiey, and M. A. Moghaddasi, "Speeds of sound, isentropic compressibilities, viscosities and excess molar volumes of binary mixtures of methylcyclohexane +2 -alkanols or ethanol at $\mathrm{T}=298.15 \mathrm{~K}$," Journal of Chemical Thermodynamics, vol. 38, no. 2, pp. 190-200, 2006.

[8] A. Pal and R. K. Bhardwaj, "Excess molar volumes and viscosities of binary mixtures of diethylene glycol dibutyl ether with chloroalkanes at 298.15 K," Indian Journal of Chemistry A, vol. 41, no. 4, pp. 706-711, 2002.

[9] A. R. Mahajan, S. R. Mirgane, and S. B. Deshmukh, "Volumetric, Viscometric and Ultrasonic studies of some amino acids in aqueous 0. $2 \mathrm{M}$. $\mathrm{LiCIO}_{4} \cdot 3 \mathrm{H}_{2} 0$ solutions at $298.15 \mathrm{~K}$," Material Science Research India, vol. 4, no. 2, pp. 345-352, 2007.

[10] A. R. Mahajan, S. R. Mirgane, and S. B. Deshmukh, "Ultrasonic studies of some amino acids in aqueous $0.02 \mathrm{M}$. $\mathrm{LiCIO}_{4} \cdot 3 \mathrm{H}_{2} \mathrm{O}$ solutions at 298.15 K," Material Science Research India, vol. 4, no. 2, pp. 373-378, 2007.

[11] A. J. Treszczanowicz and G. C. Benson, "Excess volumes for $n$-alkanols $+n$-alkanes II. Binary mixtures of n-pentanol, $n$ hexanol, $n$-octanol, and $n$-decanol $+n$-heptane," The Journal of Chemical Thermodynamics, vol. 10, no. 10, pp. 967-974, 1978.

[12] A. Ali, A. K. Nain, V. K. Sharma, and S. Ahmad, "Molecular interactions in binary mixtures of tetrahydrofuran with alkanols (C6,C8,c10): an ultrasonic and volumetric study," Indian Journal of Pure and Applied Physics, vol. 42, no. 9, pp. 666-673, 2004.

[13] H. Iloukhani, M. Rezaei-Sameti, and J. Basiri-Parsa, "Excess molar volumes and dynamic viscosities for binary mixtures of toluene $+\mathrm{n}$-alkanes $\left(C_{5}-C_{10}\right)$ at $\mathrm{T}=298.15 \mathrm{~K}$-Comparison with Prigogine-Flory-Patterson theory," Journal of Chemical Thermodynamics, vol. 38, no. 8, pp. 975-982, 2006.

[14] R. Mehra and M. Pancholi, "Temperature-dependent studies of thermo-acoustic parameters in hexane +1 -dodecanol and application of various theories of sound speed," Indian Journal of Physics, vol. 80, no. 3, pp. 253-263, 2006.

[15] C. Yang, W. Xu, and P. Ma, "Thermodynamic properties of binary mixtures of $p$-xylene with cyclohexane, heptane, octane, and $N$-methyl-2-pyrrolidone at several temperatures," Journal of Chemical and Engineering Data, vol. 49, no. 6, pp. 1794-1801, 2004.

[16] R. Meyer, M. Meyer, J. Metzger, and A. Peneloux, "Thermodynamic and physicochemical properties of binary solvent," Journal de Chimie Physique et de Physico-Chimie Biologique, vol. 68, pp. 406-412, 1971.

[17] O. Redlich and A. T. Kister, "Thermodynamics of nonelectrolyte solutions. Algebraic representation of thermodynamic properties and the classification of solutions," Industrial \& Engineering Chemistry, vol. 40, pp. 345-348, 1948.

[18] J. B. Irving, "Viscosity of binary liquid mixtures, a survey of mixture equations," NEL Report 630, National Eng Lab, East Kilbride, UK, 1977.
[19] J. B. Irving, “The effectiveness of mixture equations," NEL Report 631, National Eng Lab, East Kilbride, UK, 1977.

[20] L. Grunberg and A. H. Nissan, "Vaporisation, viscosity, cohesion and structure of the liquids," Nature, vol. 164, pp. 799-800, 1949.

[21] M. Tamura and M. Kurata, "Viscosity of binary mixture of liquids," Bulletin of the Chemical Society of Japan, vol. 25, pp. 32-37, 1952.

[22] R. K. Hind, E. McLaughlin, and A. R. Ubbelohde, "Structure and viscosity of liquids camphor+pyrene mixtures," Transactions of the Faraday Society, vol. 56, pp. 328-330, 1960.

[23] P. K. Katti and M. M. Chaudhri, "Viscosities of binary mixtures of benzyl acetate with dioxane, aniline, and m-cresol," Journal of Chemical and Engineering Data, vol. 9, no. 3, pp. 442-443, 1964.

[24] E. L. Heric, "On the viscosity of ternary mixtures," Journal of Chemical and Engineering Data, vol. 11, no. 1, pp. 66-68, 1966.

[25] E. L. Heric and J. G. Brewer, "Viscosity of some binary liquid nonelectrolyte mixtures," Journal of Chemical and Engineering, vol. 12, no. 4, pp. 574-583, 1967.

[26] R. A. McAllister, "The viscosities of lquid mixtures," AIChE Journal, vol. 6, pp. 427-431, 1960.

[27] S. Glasstone, K. J. Laidler, and H. Eyring, The Theory of Rate Process, McGraw-Hill, New York, NY, USA, 1941.

[28] R. K. Nigam and B. S. Mahl, "Molecular interaction in binary liquid mixtures of dimethylslphoxide with chlroehanes \& chlroehenes," Indian Journal of Chemistry, vol. 9, p. 1255, 1971.

[29] R. J. Fort and W. R. Moore, "Viscosities of binary liquid mixtures," Transactions of the Faraday Society, vol. 62, pp. 11121119, 1966.

[30] K. Ramamoorty and P. S. Varadachari, "Study of some binary liquid mixtures," Indian Journal of Pure and Applied Physics, vol. 11, p. 238, 1973.

[31] P. J. Flory, "Statistical thermodynamics of liquid mixtures," Journal of the American Chemical Society, vol. 87, no. 9, pp. 1833$1838,1965$.

[32] A. Abe and P. J. Flory, "The thermodynamic properties of mixtures of small, nonpolar molecules," Journal of the American Chemical Society, vol. 87, no. 9, pp. 1838-1846, 1965.

[33] I. Prigogine, Molecular Theories of Solutions, North-Holland, Amsterdam, The Netherlands, 1957.

[34] D. Patterson and G. Delmas, "Corresponding states theories and liquid models," Discussions of the Faraday Society, vol. 49, pp. 98-105, 1970.

[35] P. Tancrède, P. Bothorel, P. De St. Romain, and D. Patterson, "Interactions in alkane systems by depolarized Rayleigh scattering and calorimetry. Part 1.-Orientational order and condensation effects in $\mathrm{n}$-hexadecane + hexane and nonane isomers," Journal of the Chemical Society, Faraday Transactions 2, vol. 73, no. 1, pp. 15-28, 1977.

[36] P. De St. Romain, H. T. Van, and D. Patterson, "Effects of molecular flexibility and shape on the excess enthalpies and heat capacities of alkane systems," Journal of the Chemical Society, Faraday Transactions 1, vol. 75, pp. 1700-1707, 1979.

[37] A. T. Rodriguez and D. Patterson, "Excess thermodynamic functions of $n$-alkane mixtures. Prediction and interpretation through the corresponding states principle," Journal of the Chemical Society, Faraday Transactions 2, vol. 78, no. 3, pp. 501$523,1982$.

[38] T. M. Aminabhavi, K. Banerjee, and R. H. Balundgi, “Thermodynamic interactions in binary mixtures of 1-chloronaphthalene 
and monocyclic aromatics," Indian Journal of Chemistry A, vol. 38, no. 8, pp. 768-777, 1999.

[39] J. A. Riddick, W. B. Bunger, and T. K. Sakano, Techniques of Chemistry, Organic Solvents. Physical Properties and Methods of Purifications, vol. 2, John Wiley \& Sons, New York, NY, USA, 1986.

[40] A. Krishnaiah and P. R. Naidu, "Excess thermodynamic properties of binary liquid mixtures of 1,2-dichloroethane with normal alkanes," Journal of Chemical and Engineering Data, vol. 25, no. 2, pp. 135-137, 1980.

[41] E. Aicart, G. Tardajos, and M. Díaz Peña, "Isothermal compressibility of cyclohexane $+n$-hexane, cyclohexane $+n$-heptane, cyclohexane + n-octane, and cyclohexane + n-nonane," Journal of Chemical and Engineering Data, vol. 25, no. 2, pp. 140-145, 1980.

[42] J. D. Pandey and N. Pant, "Surface tension of ternary polymeric solution," Journal of the American Chemical Society, vol. 104, no. 12, pp. 3299-3302, 1982.

[43] A. S. Al-Jimaz, J. A. Al-Kandary, and A.-H. M. AbdulLatif, "Acoustical and excess properties of \{chlorobenzene $+1-$ hexanol, or 1-heptanol, or 1-octanol, or 1-nonanol, or 1-decanol\} at $(298.15,303.15,308.15$, and 313.15) K," Journal of Chemical and Engineering Data, vol. 52, no. 1, pp. 206-214, 2007.

[44] E. Aicart, G. Tardajos, and M. Diaz Peña, "Isothermal compressibility of cyclohexane-n-decane, cyclohexane-n-dodecane, and cyclohexane-n-tetradecane," Journal of Chemical and Engineering Data, vol. 26, no. 1, pp. 22-26, 1981.

[45] V. A. Bloomfield and R. K. Dewan, "Viscosity of liquid mixtures," Journal of Physical Chemistry, vol. 75, no. 20, pp. 31133119, 1971.

[46] A. Jouyban, M. Khoubnasabjafari, Z. Vaez-Gharamaleki, Z. Fekari, and W. E. Acree Jr., "Calculation of the viscosity of binary liquids at various temperatures using Jouyban-Acree model," Chemical and Pharmaceutical Bulletin, vol. 53, no. 5, pp. 519523, 2005.

[47] A. Jouyban, A. Fathi-Azarbayjani, M. Khoubnasabjafari, and W. E. Acree Jr., "Mathematical representation of the density of liquid mixtures at various temperatures using Jouyban-Acree model," Indian Journal of Chemistry A, vol. 44, no. 8, pp. 15531560, 2005.

[48] A. Krishnaiah and P. R. Naidu, "Excess thermodynamic properties of binary liquid mixtures of 1,2-dichloroethane with normal alkanes," Journal of Chemical and Engineering Data, vol. 25, no. 2, pp. 135-137, 1980. 

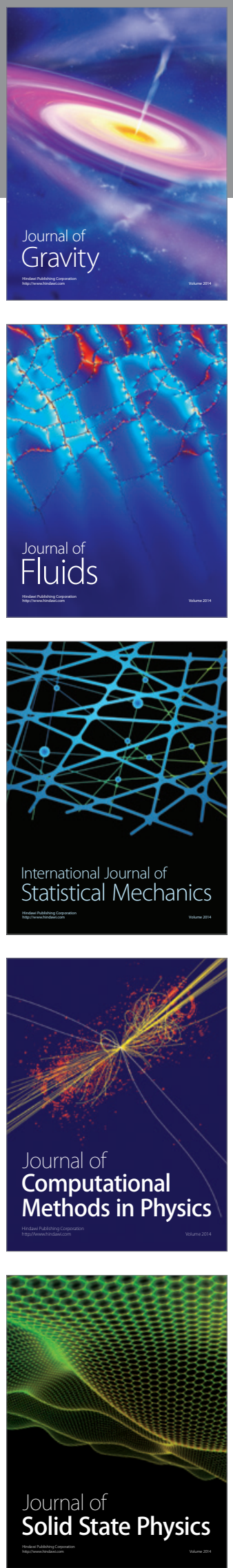

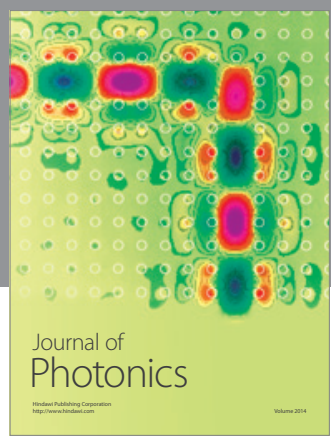

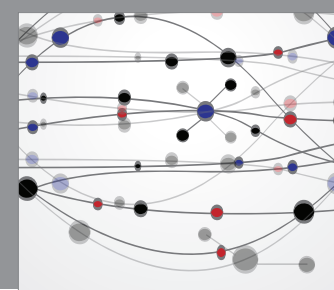

The Scientific World Journal

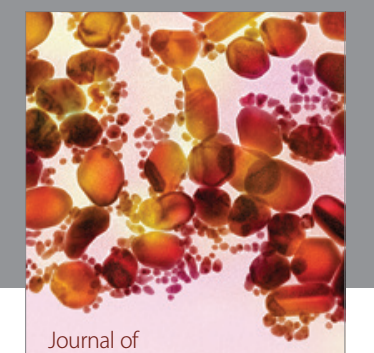

Soft Matter
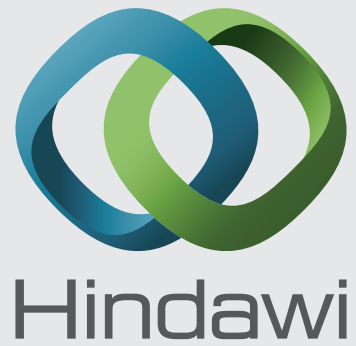

Submit your manuscripts at

http://www.hindawi.com
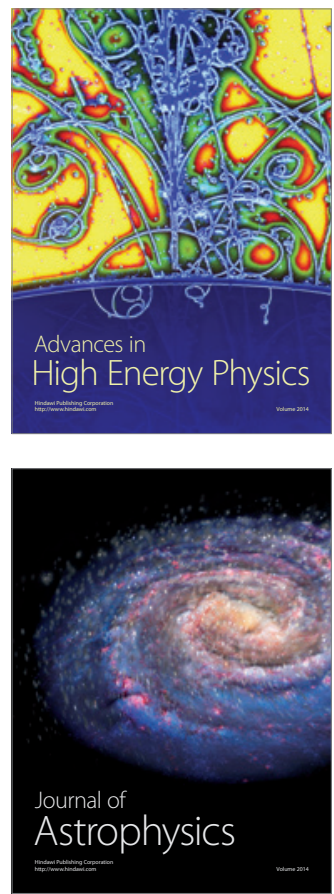
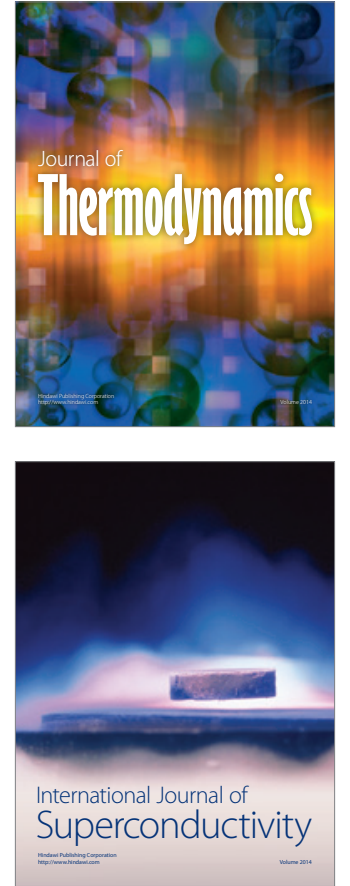
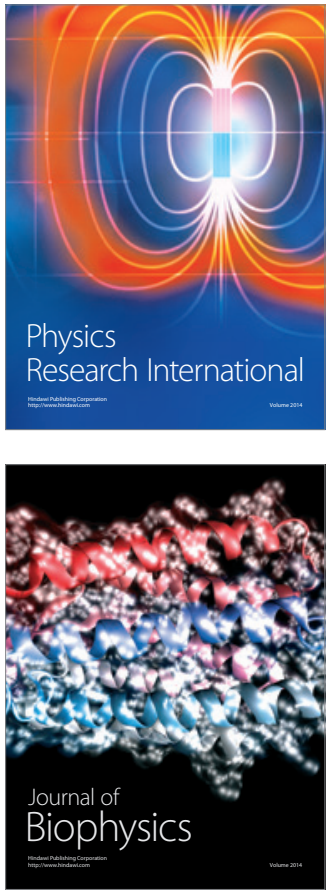
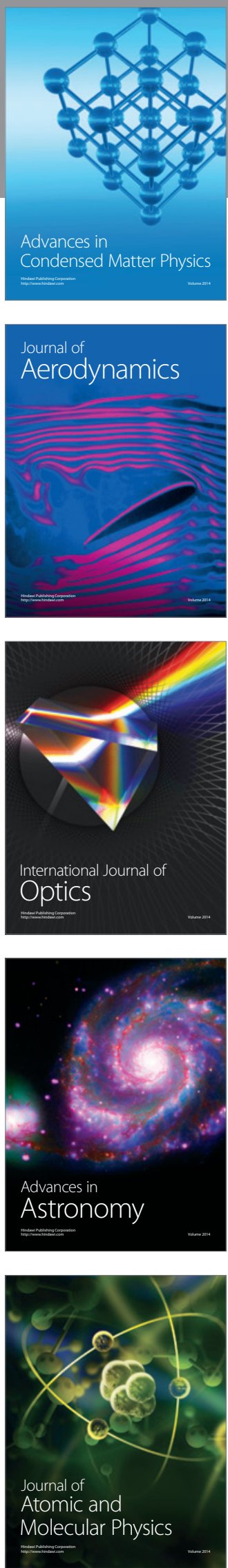